\title{
Frequency of Bicycle Commuting: Internet-Based Survey Analysis
}

\author{
Monique A. Stinson \\ Chicago Area Transportation Study (CATS) \\ 300 West Adams Street, 2nd Floor \\ Chicago, Illinois 60606 \\ Phone: (312) 793-5664, Fax: (312) 793-3481 \\ Email:mstinson@catsmpo.com
}

\section{Chandra R. Bhat}

The University of Texas at Austin, Department of Civil Engineering

1 University Station C1761, Austin, Texas, 78712-0278

Phone: (512) 471-4535, Fax: (512) 475-8744

Email: bhat@mail.utexas.edu

\section{TRB 2004: FOR PRESENTATION \& PUBLICATION}

Paper \# 04-3493 


\begin{abstract}
This research uses an ordered-response model to evaluate the factors that impact bicycle frequency use for an individual's commute to and from work. The data used for this paper were gathered during an original survey effort conducted over the Internet in 2002. The paper presents empirical results and discusses the policy implications of these results for urban planning. In addition, the paper descriptively analyzes the deterrents and facilitators of bicycle commuting as reported by respondents in the survey.

Several findings from this research contribute to the state of the knowledge in bicycle commuting. First, availability of showers or clothing lockers at the workplace does not appear to inspire bicycle commuters to commute by bicycle more frequently. Second, using a bicycle for non-work trip purposes increases an individual's frequency of commuting by bicycle to work. Other important results indicate that non-bicycle commuters either have misconceptions about the dangers of bicycling, or else they lack convenient, safe route options for bicycling to work.

Practitioners can use the ordered response model to estimate an individual bicycle commuter's frequency of commuting by bicycle. The results can also help practitioners estimate the effects on non-motorized mode share of programs that compete for funds to provide bicycling safety education, bicycle parking, and promotion of bicycling.
\end{abstract}




\section{INTRODUCTION}

Examining the factors that influence frequency of commuting to work by bicycle is important for several reasons. First, the routine physical exercise provided by frequent bicycle use has significant health benefits for the bicycling individual (1). Second, every trip made with a bicycle is a non-polluting trip and helps to improve air quality. Decreased emissions can also be used by Metropolitan Planning Organizations in large air quality non-attainment urban areas as a means to make progress toward attainment of air quality standards. Third, frequent utilitarian bicycle use can help alleviate automobile-related problems such as traffic congestion-related delays and loss of natural resources. In each of these three contexts, more frequent bicycle use has a greater positive impact than less frequent bicycle use.

An understanding of the frequency of bicycle use is especially useful in the context of work trips. Work trips typically comprise a significant portion of a worker's weekly trips. Therefore, focusing policies on the work commute has the potential for significant pay-offs in terms of public health benefits, traffic congestion alleviation and mobile source emissions reduction. In addition, about half of all work trips are within easy bicycling distance (2). Socialrecreational trips and shopping trips, on the other hand, often vary in logistical needs, making these trips slightly more difficult to plan for bicycling. Therefore, the regularity of the work trip (for most workers) makes the work commute a reasonable focus of efforts to increase bicycling frequency.

In summary, there are many compelling reasons for focusing bicycle-related research and policies on work trips. This motivates the research in the current paper. Specifically, we identify and examine the determinants of the frequency of bicycle use for an individual's work commute. The factors considered in our analysis include work characteristics, demographic characteristics, bicycle infrastructure facilities, seasonal effects, and location attributes. In addition, we also present our findings from an examination of the facilitators and deterrents of bicycling to work.

The rest of this paper is organized as follows. The next section discusses related research and positions the current work in the broader context of this earlier research. Section 3 presents the data source and describes the sample used in analysis. Section 4 descriptively examines the facilitators of, and deterrents to, bicycle commuting. Section 5 discusses the model structure used in the analysis of bicycle commuting frequency. Section 6 presents the empirical results. Finally, Section 7 concludes the paper by summarizing the important findings and discussing policy implications.

\section{PREVIOUS RESEARCH}

The authors have been unable to locate any documented research efforts in the literature that specifically model bicycle commuting frequency. However, numerous researchers have examined the sociodemographic characteristics of bicycle commuters using data obtained from surveys. Furthermore, several aggregate-level studies have examined sociodemographic, transportation network, and land use characteristics that contribute to bicycle mode share.

The following literature review is structured as follows. First, characteristics of bicycle commuters as found in previous studies are described. Second, previous studies focusing on the deterrents to bicycle commuting are discussed. Third, studies examining the frequency of commuting by bicycle to work are presented. Finally, studies that have examined bicycle mode shares at the aggregate level are discussed. 


\subsection{Characteristics of Bicycle Commuters}

Numerous bicycle commuter-related surveys from different regions of the U.S. have been analyzed in earlier studies (3-5). These studies have provided several useful insights into the demographic characteristics of bicycle commuters. Specifically, the studies indicate that men are more likely to bicycle to work than women. In addition, younger people, on average, bicycle to work more than older people do. Goldsmith summarizes several surveys that indicate that the effect of household income is less clear (6). Finally, years of cycling experience also appear to be positively correlated with willingness to commute by bicycle (7).

\subsection{Deterrents to Bicycle Commuting}

Surveys of the general commuting population indicate that the most important factors in choosing a commute mode are travel time, convenience, needing a car for work or other purposes, and cost (6). Therefore, many avid bicyclists do not choose to bicycle to work because of long commute distances and the consequent high travel times that bicycling would entail (6, 8). In another related study, Antonakos found in a sample of 552 bicyclists on a recreational tour that the average commuting distance of all workers in the sample was $20 \mathrm{~km}$, while the average commuting distance of the subsample of bicycle commuters was $10.8 \mathrm{~km}(7)$.

Other deterrents to bicycle commuting to work include dangerous traffic conditions, lack of bicycle infrastructure facilities (bicycle lanes and separate paths, bicycle parking, shower/locker rooms at work, etc.), physical exertion (especially in hilly terrain), and adverse weather conditions $(3,6,9-12)$. International studies indicate similar deterrents to bicycle commuting in other countries (13-18) [for example, Björsson (16) and Perala (17) document the impact of adverse weather conditions on bicycle commuting; Bach and Pressman also identify many of the deterrents listed earlier (18)] .

\subsection{Frequency of Bicycle Commutes}

Several studies have examined the frequency of bicycle commuting through descriptive analyses (rather than rigorous modeling efforts). These analyses provide valuable insights into bicycle commuting frequency and its determinants.

Tanaboriboon examined the characteristics of Shanghai commuters who bicycle frequently to work and found that frequent bicycle commuters have a higher tolerance for riding longer distances, and that men are willing to ride longer distances than women (13). A few studies indicate that certain weather conditions (rainfall, cloud cover and temperature) are important determining factors of bicycle use for commuting $(14,15)$. Hope found that better facilities en route (for example, bicycle lanes), bicycle parking availability at work, and cyclist training encourage frequent bicycle commuting (10). Finally, Neimeier et al., in a survey of bicycle commuters in Seattle, found that males made, on average, 6.7 one-way work commute trips by bicycle per week, while females made an average of 5.8 one-way work commute trips by bicycle per week (19). The results indicated no significant influence of household size, household income, and number of motorized vehicles in the household on bicycle commuting frequency.

\subsection{The Decision to Bicycle to Work: Aggregate Studies}

Numerous research efforts have examined factors influencing bicycle commuting at the aggregate level. For example, extreme cold weather has a dramatic negative impact on bicycle commute rates (5). The presence of good bicycle facilities en route, on the other hand, increases 
the bicycle mode share for the commute (20). Other factors that appear to increase bicycle mode share are the presence of a large college or university, higher urban densities, relatively mild climates, link and network "friendliness" for non-motorized travel, supporting policies for use of non-motorized modes (e.g., bicycle parking and educational programs), good land use mix, and total non-motorized trip making $(6,21-23)$.

\subsection{Summary of Previous Research}

Previous efforts have examined factors affecting the choice and frequency of the bicycle as a commute mode. These factors include weather, land use density, characteristics of the transportation network (including provision of bicycle facilities), availability of bicycle parking/other facilities at work, sex, distance (or travel time) to work, physical exertion, cost, the necessity of a car for errands before, after, or during work, and population characteristics. In addition, several previous studies have examined the average bicycle commute frequencies from survey samples.

This paper contributes to the existing research by examining individual frequency of bicycling to work using data from a wide range of geographic areas and climates. We present a model that evaluates several determinants of bicycle commuting simultaneously to draw conclusions about the relative impacts of various determinants. In contrast, almost all earlier studies have only descriptively examined the determinants of bicycle commuting frequency. These descriptive studies partition the sample based on one or two demographic/other characteristics and make inferences by comparing the average bicycle commuting frequency across the groups. While insightful, these studies do not control for the effect of other factors when studying the impact of any one factor. By considering all factors simultaneously within a unifying econometric framework, our current study provides important information on the magnitude of effects of determinant variables, which can help in the effective targeting and positioning of policies aimed at increasing bicycle commute rates.

\section{DATA SOURCE AND SAMPLE DESCRIPTION}

\subsection{Data Source}

The data used for this research were collected in a survey designed by the authors and administered on the World Wide Web (24). Respondents were solicited from bicycle-related Internet sources (listserves, websites, and newsletters) and from non-bicycle-related listserves. Nearly 3,500 respondents completed and submitted their responses at the survey website between January and March, 2002. A pdf version of the survey is available for download on the authors' websites $(25,26)$.

\subsection{Data Assembly}

This paper undertakes three different kinds of analyses. The first analysis is the descriptive examination of the deterrents to bicycling to work, which uses the survey responses of all individuals who responded to the question seeking information on these deterrents. The sample size for this analysis is 2,822 and includes bicycle commuters as well as non-bicycle commuters (bicycle commuters are defined as those who used a bicycle to commute at least three times in a year). The second analysis is the descriptive examination of the reasons for using the bicycle for commuting, which is restricted to the sample of bicycle commuters in the survey who answered this question. The sample size for this second analysis is 2,548. Finally, the third analysis is the 
modeling of bicycle commuting frequency. This analysis uses a subset of the sample used for the second analysis, and includes only those bicycle commuters who live in the United States or Canada, who responded to at least one of the four season-based questions regarding bicycling frequency (see Figure 1 for a sample question for the Spring season), and who provided information on all the independent variables used to explain bicycling commute frequency. The sample size for this third analysis is 2,144.

The data assembly for the first and second analyses is straightforward. For the third analysis, the responses to the season-based questions on bicycle commuting frequency are stacked vertically. Thus, each row in this dataset corresponds to an individual-season combination (the total number of records in this data set is 2,144 individuals $\mathrm{x} 4$ seasons $=8,576$ records). The data assembly was conducted using the SAS statistical software. The final data sample was imported into LIMDEP (for LIMited DEPendent variable estimation software) for econometric estimation.

\subsection{Sample Description}

The final sample used in the econometric estimation of bicycle commuting frequency has the following characteristics. About $20 \%$ of respondents are female ( $80 \%$ male). The age distribution is fairly normal and centered (as expected) on the working population, with the majority (94\%) of respondents in the 25-64 years age group. The distribution of annual household income (in U.S. dollars) is as follows: less than $\$ 20,000$ (4\%), $\$ 20,000-\$ 30,000$ (5\%), $\$ 30,000-\$ 40,000$ (9\%), \$40,000-\$50,000 (9\%), \$50,000-\$60,000 (10\%), \$60,000-\$75,000 (15\%), \$75,000$\$ 100,000$ (22\%), and greater than $\$ 100,000$ (26\%). The distribution of sample incomes is higher than U.S. population incomes, but this probably biases the sample only marginally (21). The number of years of bicycle commuting experience for those in the survey who have some bicycle commuting experience has the following distribution: less than one year (13\%); 1-3 years (25\%); $3-5$ years (17\%); 5 -10 years (21\%); 10-20 years (15\%); and over 20 years $(9 \%)$.

In addition to the several individual-level attributes listed in the previous paragraph, we also included independent variables that capture the interaction effects of season with regional residential location. Six North American regions were identified; the states classified into each region, the general climactic conditions in each region, and the percentage of individuals from each region are presented in Table 1.

\section{DESCRIPTIVE ANALYSIS OF DETERRENTS AND REASONS FOR BICYCLE COMMUTING}

\subsection{Deterrents to Bicycle Commuting}

One of the questions in the survey sought information on the perceived deterrents to use the bicycle for commuting. All survey participants were asked to respond to this question. Respondents were provided several pre-specified categories and they could select more than one deterrent category. Respondents also had the option of writing in a deterrent that was not in the pre-specified list. Table 2 provides the results for the entire group of respondents (bicycle commuters and non-bicycle commuters) as well as separately for non-bicycle commuters and bicycle commuters. Among the most dominant deterrents for bicycle commuting are unpleasant weather, personal issues (e.g., too busy), and not enough daylight to ride safely. The substantial impact of unpleasant weather and inadequate daylight may be a consequence of the survey being administered in spring and the question on deterrents being posed in the context of the "past 
three months". Thus, the impacts of unpleasant weather and inadequate daylight may be more exaggerated than is really the case. Other significant deterrents include injury or illness and the need to pursue errands with an automobile during the workday or the work commute.

The most interesting results from the analysis of deterrents arise from a comparison of the responses of non-bicycle commuters and bicycle commuters. Bicycle commuters more often cite unpleasant weather and an injury/illness as being deterrents than do non-bicycle commuters. On the other hand, non-bicycle commuters have a much higher likelihood of identifying lack of daylight, unsafe neighborhoods, distance to work being too long, dangerous traffic, and lack of bicycle facilities as being deterrents than bicyclists. While some of these differences may be reasonable (for example, bicycle commuters may tend to be located closer to work than nonbicycle commuters), others may be due, at least in part, to misperceptions and misconceptions on the part of non-bicycle commuters regarding bicycling to and from work (for example, the potentially exaggerated negative perceptions about lack of daylight, unsafe conditions and dangerous traffic environments associated with bicycling). Appropriate informational campaigns or bicycling safety classes may reduce some of these potential misperceptions about traveling by bicycle, although many non-bicycle commuters simply do not have a route option that is safe for bicycling. Other policy initiatives could improve safety for bicyclists by increasing traffic law enforcement or improving skills of automobile drivers (e.g., by mandating more thorough drivers' education classes). Further, policies that promote denser land use and land mix, and discourage urban sprawl, could reduce the dependence on automobiles to pursue errands and encourage bicycle use. In addition, denser developments would bring commuters closer to their work place, making it easier for individuals to bicycle to work. Finally, policies that improve the bicycle transportation infrastructure could also encourage bicycle commuting by making it more safe, convenient, and comfortable (24).

\subsection{Reasons for Bicycle Commuting}

The survey, in addition to seeking information on deterrent from all respondents, also obtained information on the reasons for bicycling to work from bicycle commuters (those who bicycled to work at least three times during the year). The results are presented in Table 3. Clearly, the dominant reasons for using the bicycle within the group of bicycle commuters is the fitness/health benefits and the pleasure/enjoyment accruing from bicycle use. Furthermore, concerns regarding automobile use (for example, concern for the natural environment) are an important consideration.

It is important to note from Table 3 that almost all bicycle commuters make the conscious choice of using the bicycle and are not "captive" to bicycle use, as reflected by the very small percentage $(1.1 \%)$ who indicate that they bicycle because of the unavailability of a private automobile.

\section{MODEL STRUCTURE AND ESTIMATION}

In this section, we present the structure for the model of bicycle commuting frequency. The survey sought information from bicycle commuters regarding their frequency of commuting by bicycle for each of the four seasons in one of five ordinal categories (see Figure 1): (a) never, (b) 1-2 times a month, (c) once a week, (d) 2-3 times a week, and (e) 4-5 days or more per week.

A model structure that recognizes the ordinal nature of bicycle commuting frequency is the ordered-response formulation. The ordered-response formulation was initially proposed by McKelvey and Zavonia (27) and has been used extensively in the transportation literature for 
analyzing the frequency of stop-making and trip-making (28-30). In the context of bicycle commuting frequency, the ordered-response mechanism postulates the presence of a latent continuous bicycle commuting propensity $y_{q s}^{*}$ for individual $q$ and season $s$. This latent propensity is assumed to be a linear function of a relevant vector of exogenous variables $x_{q s}$ and a standard normally distributed error term $\varepsilon_{q s}$. The latent propensity $y_{q s}^{*}$ characterizes the actual reported frequency of bicycle commuters, $y_{q s}$, through a set of threshold bounds:

$$
\begin{array}{rlrl}
y_{q s}^{*} & =\beta^{\prime} x_{q s}+\varepsilon_{q s}, \varepsilon_{q s} \sim N(0,1) & & \\
y_{q s} & =0 \text { (never) } & & \text { if } \quad y_{q s}^{*} \leq 0 \\
& =1(1-2 \text { times a month) } & & \text { if } 0<y_{q s}^{*} \leq \mu_{1} \\
& =2 \text { (once a week) } & & \text { if } \mu_{1}<y_{q s}^{*} \leq \mu_{2} \\
& =3(2-3 \text { times a week) } & & \text { if } \mu_{2}<y_{q s}^{*} \leq \mu_{3} \\
& =4(4-5 \text { times or more a week) }) & \text { if } \mu_{3}<y_{q s}^{*}
\end{array}
$$

In the above equation, $x_{q s}$ includes a constant. The normalization of the variance of the error term $\varepsilon_{q s}$ to 1 , and the lowest threshold to 0 , are innocuous scale and range normalizations, respectively, needed for model identification $(27,29)$. The $\mu$ 's represent the threshold bounds.

The probability that individual $q$ will have a bicycle commuting frequency $k(k=0,1,2$, $3,4)$ in season $s$ can be obtained from Equation (1) as

$$
P\left[y_{q s}=k\right]=\Phi\left(\mu_{k}-\beta^{\prime} x_{q s}\right)-\Phi\left(\mu_{k-1}-\beta^{\prime} x_{q s}\right), \mu_{-1}=-\infty, \mu_{4}=+\infty
$$

Assuming independence of the error terms across individuals and seasons, and defining a set of dummy variables $\delta_{q s k}\left(\delta_{q s k}=1\right.$ if individual $q$ selects the bicycle commuting frequency category $k$ in the $s^{\text {th }}$ season, and $\delta_{q s k}=0$ otherwise), the relevant log-likelihood function for estimation of the $\beta$ parameter vector and the $\mu$ threshold bounds is:

$$
L=\sum_{q} \sum_{s} \delta_{q s k} \log \left[\Phi\left(\mu_{k}-\beta^{\prime} x_{q s}\right)-\Phi\left(\mu_{k-1}-\beta^{\prime} x_{q s}\right)\right]
$$

The log-likelihood function can be maximized using standard econometric software (LIMDEP was used in the current analysis).

\section{EMPIRICAL RESULTS}

Five groups of variables were considered in the empirical analysis: (a) Demographic variables, (b) General bicycle use and experience variables, (c) Work-related characteristics, (d) Residential location attributes, and (e) Region of residence and seasonal effects. Several different variables were considered within each class and interaction effects of variables across the various groups were also explored. The final specification was based on a systematic process of 
eliminating statistically insignificant variables and combining variables when their effects were not statistically different. This process was informed by intuitive considerations and earlier research.

The final empirical results from the ordered response model of bicycle commuting frequency are provided in Table 4 . The reader will note that a positive (negative) coefficient on a variable indicates that an increase in the variable has the effect of increasing (decreasing) the propensity to commute by bicycle. These directional effects of variables are interpreted in Section 6.1, while Section 6.2 discusses the relative impacts of variables.

\subsection{Variable Effects}

The effects of explanatory variables on the frequency of bicycle commuting are discussed by variable category in the subsequent sections.

\subsubsection{Effect of Demographic Variables}

The effects of demographics indicates that the propensity to use the bicycle for commuting is greater among men (relative to women) and among individuals who have fewer number of cars in their household. The former result is consistent with the findings from the literature. The latter effect is rather intuitive, though it remains an open question whether a lower number of motorized vehicles causes a higher bicycle commuting propensity or whether individuals (as part of their household) decide on the number of cars based on their propensity to commute by bicycle (age effects and income effects were also considered within the category of demographics, but did not turn out to be statistically significant).

\subsubsection{Effect of Bicycle Use and Experience Variables}

The impact of bicycle use and experience variables indicates that the number of years of bicycling experience to work increases the propensity to commute by bicycle. This result has several possible interpretations. For example, it suggests that, like other modes of commuting, bicycle use for commuting is also habit-forming. Alternatively, it may be that comfort in bicycle commuting comes from experience. Bicyclists with more experience in bicycle commuting are likely to feel more comfortable riding with motorized traffic and carrying cargo, and are more likely to have become adept at maintaining a professional appearance at the workplace after riding than less experienced bicycle commuters. Similar interpretations may be provided to explain the positive impact of the number of trip purposes pursued by bicycle on the propensity to commute by bicycle (trip purposes listed in the survey included exercise, visiting friends/family, racing, stunt-riding, and other recreation).

\subsubsection{Effect of Work-Related Characteristics}

Among the set of work-related characteristics, the negative sign on distance to work is as one would expect; people residing farther away from work are less likely to commute by bicycle than those living closer to work. Also, working in an urban location is likely to increase the propensity to commute by bicycle. This latter result suggests that urban sprawl or low density land use creates unique challenges for people who might otherwise wish to bicycle to work routinely. For instance, in rural and suburban areas, even when distance is not prohibitive for bicycle commuting, relatively direct routes from home to work often include travel on very highspeed throughways with no special bicycle-use facilities. Finally, in the set of work-related 
characteristics, the results show that presence of bicycle racks or bicycle locker facilities at work increases the likelihood of commuting by bicycle.

Two other workplace variables were also considered in our analysis: presence of showers and clothing lockers. Surprisingly, neither variable was statistically significant. There are several possible explanations for this result. First, many commuter bicyclists probably are not uncomfortable with some low degree of sweating and do not feel the need to change clothing. Furthermore, many popular fabrics dry quickly. Besides, many commuter bicyclists may not bicycle to work strenuously enough to become drenched in sweat (in addition, most ride to work in the early morning when it is not very hot outside). Second, restroom stalls are a handy place to clean up and change clothes, and most workers have a closet or similar facility at their workplace to hang clothes. Third, the extra time incurred by showering is itself an inconvenience. In summary, while commuter bicyclists (and others who exercise en route to work) probably would welcome showers and clothing lockers at the workplace, such facilities do not appear to impact the frequency of commuting by bicycle.

In addition to the work-related variables discussed thus far, flexibility of the work schedule was also examined in our analyses, but was statistically insignificant or only marginally significant in each specification. A possible explanation for the insignificance of flexible work hours is the reliability of travel time by bicycle. Factors that affect travel time reliability for users of other modes (especially late bus arrivals for transit users and congestion for bus and automobile users) generally do not affect travel times for bicycle users. Rain, snow and ice, in contrast, require slower bicycling speeds for safety reasons; however, as we will discuss later, inclement weather diverts many bicycle commuters to other modes anyway.

\subsubsection{Home Location Variables}

The home location variables in Table 4 indicate the higher bicycle commuting propensity of individuals residing in urban areas relative to individuals residing in suburban and rural areas. Furthermore, individuals in suburban areas are more likely to commute by bicycle than individuals residing in rural areas. These results mirror those of the work related location variables, and have the same substantive interpretations as provided earlier for the work location variables.

\subsubsection{Effects of Region of Residence and Season}

The impact of the region of residence and season are very highly statistically significant for the most part. These variables are introduced with the base category being the west coast and winter season. Several important observations may be made here. First, the propensity to commute by bicycle in the winter season is lowest in Canada, low in the midwestern and northeastern regions of the U.S., moderate in the mideastern and southwestern U.S., and highest in the west coast (see the magnitude and the signs on the "winter" variables across the regions). This is clearly a reflection of the negative impact of harsh winters (frigid temperatures, snow, and ice) on the commuting to work by bicycle. Second, in all regions, workers commute by bicycle more frequently in the summer than in the spring or fall, and less frequently in the winter than during other seasons. Third, the variation in propensity to commute by bicycle across seasons is lowest for the west coast and lower for the southwestern and southeastern U.S. relative to other nonwest coast regions. This is perhaps a reflection of the smaller variation in weather conditions across seasons in these three regions compared to other regions. Fourth, the propensity to commute is highest in Canada compared to other regions during the summer season. A possible 
reason for this is that, in contrast to the U.S., Canada has taken greater strides in planning for and accommodating utilitarian bicycle travel. Another potential reason is that the relatively mild temperatures of Canadian summers make a more comfortable environment for bicycling to work.

\subsubsection{Threshold Parameters}

The constant and threshold parameters listed toward the end of Table 4 do not have any substantive behavioral interpretations; they simply serve the purpose of associating the observed frequency categories to the underlying propensity to commute by bicycle.

\subsubsection{Model Fit}

The log-likelihood at convergence of the model is -10241 , while the log-likelihood of the model that predicts equal shares in all the five bicycle commuting frequency categories is -11634 . A statistical comparison of these two models using a likelihood ratio test provides a test statistic value of 2788, which is substantially larger than the chi-squared value with 25 degrees of freedom at any reasonable level of significance. This indicates that the independent variables used in the model provide substantial value in predicting the frequency of commuting by bicycle.

\subsection{Relative Impacts of Selected Variables}

The parameter effects in Table 4 show the directionality of effect of different sets of variables. Some of the magnitudes of the variables can also be directly compared, such as the effects of regions of residence and season, because all these region/season variables are dummy variables. However, the relative impacts of other variables such as work distance and number of cars in a household cannot be obtained directly from the coefficient values because of the different ranges of these variables. One simple approach to assess the relative importance of each variable is to compute the contribution of each variable to bicycle commuting propensity at the average value of the variable, or for dummy variables when the feature represented by the variable is present.

We consider three variables that are amenable to policy actions and compute their relative impacts. The variables are (a) distance to work, (b) number of cars in a household, and (c) presence of bicycle rack or bicycle locker. The computed contributions to the propensity of commuting by bicycle for these variables are as follows: (a) distance to work: -0.04 (coefficient value) $x 8.16$ (mean commute distance in sample) $=-0.33$, (b) number of cars in a household $=$ -0.30 , and (c) presence of bicycle rack or locker $=0.16$. Clearly, these results show that distance to work is the most dominant determinant of commuting by bicycle, followed by number of cars in a household, and finally presence of bicycle rack or locker. On the other hand, from a policy action standpoint, installing bicycle racks or lockers at the workplace is perhaps the easiest initiative to increase bicycle commuting frequency.

\section{SUMMARY AND CONCLUSIONS}

This paper has examined the factors that influence the decision of commuters to bicycle to work. Three different kinds of analyses have been undertaken. The first examines the deterrents to commuting by bicycle, the second studies the reasons for bicycle commuting among those who commute by bicycle, and the third represents a formal modeling of bicycle commuting frequency. All these analyses are undertaken using a bicycle survey conducted over the Internet in 2002 by the authors at The University of Texas.

The results from our analyses provide several important insights. First, the dominant deterrents to bicycle commuting are unpleasant weather and inadequate daylight. Other 
significant impediments include the need to pursue errands during work or the commute to or from work, and injury/illness considerations. Second, it appears that there are some misperceptions and misconceptions on the part of non-bicyclist commuters about the feasibility and dangers of bicycling. Some of these non-bicyclist commuters may have an exaggerated sense of unsafe riding conditions and dangers associated with the lack of bicycle facilities or lack of daylight. However, other non-bicyclist commuters may not have a safe bicycling route option; or, they may have poor night vision. The feasibility of bicycle commuting for many non-bicycle commuters may improve with bicycling safety classes, driving safety classes, increased enforcement of traffic laws, or more lighting in dark areas. Third, the primary reasons for commuting by bicycle among bicycle commuters are the health/fitness benefits, the pleasure/enjoyment accruing from bicycle use, and the perceived contribution toward alleviating environmental problems. Fourth, demographics, overall bicycle usage and bicycle commuting experience, work-related characteristics, location of home and work, and region of residence/season have important effects on the propensity to commute by bicycle. The regional/seasonal effects are very intuitive, and suggest higher bicycle usage for commuters during the summer months and lowest usage during the winter months. The propensity to bicycle to work is lowest during the winter season in regions with severe cold climates. As expected, individuals residing and working in more dense areas (urban areas) have a higher likelihood of commuting to work by bicycle, presumably due to better bicycle-related infrastructure. Also, distance to work has a very strong influence on the propensity to commute by bicycle. Other factors impacting bicycle commuting include general bicycling experience, and presence of a bicycle rack or bicycle locker at the workplace.

The results of this research have several important policy implications for cities and regions that hope to increase bicycle use for commuting. The easiest policy initiative to encourage bicycle commuting is the installation of bicycle parking facilities at employment centers. In fact, many urban areas already have such parking facilities in place. Another policy initiative is bicyclist training and education, to enhance the self-perceived experience level of a potential commuter bicyclist. Policies that are worthwhile but perhaps more difficult to implement are those that aim to decrease the number of motorized vehicles in a household or decrease commute distances in the population.

\section{ACKNOWLEDGEMENTS}

Lisa Barden and Gus Castellanos of The University of Texas at Austin College of Engineering provided invaluable assistance in developing and tailoring the online survey software, Survey on the Spot, used in this research. The survey was administered online on a College of Engineering website. The authors are grateful to Lisa Weyant for her help in typesetting and formatting this document. The peer reviewers also provided valuable comments that helped improve the paper content. 


\section{REFERENCES}

1. Frank, L.D., Engelke, P.O. and T.L. Schmid. Health and Community Design: The Impact of the Built Environment on Physical Activity. Island Press, Washington, 2003.

2. Moritz, W. Survey of North American Bicycle Commuters: Design and Aggregate Results. In Transportation Research Record 1578, TRB, National Research Council, Washington, D.C., 1997, pp 91-101.

3. Deakin, E. Utilitarian Cycling: A Case Study of the Bay Area and Assessment of the Market for Commute Cycling. Research Report: FHWA/CA/TP-85/1, UCB-ITS-RR-85-9. Berkeley, CA, 1985.

4. Williams, J. and J. Larson. Promoting Bicycle Commuting: Understanding the Customer. Transportation Quarterly, Vol. 50, No. 3, 1996, pp. 67-78.

5. Ottawa-Carleton Cycling Advisory Group. Commuter Cycling in Ottawa-Carleton: A Survey. Department of Engineering and Works, City of Ottawa, Ontario, Canada, 1992.

6. Goldsmith, S. Reasons Why Bicycling and Walking Are Not Being Used More Extensively As Travel Modes. Publication No. FHWA-PD-92-041, Federal Highway Administration National Bicycle and Walking Study: Case Study \#1, 1992, http://www.fhwa.dot.gov/safety/fourthlevel/pdf/Case1.pdf. Accessed 2003 July 29.

7. Antonakos, C. Environmental and Travel Preferences of Cyclists. In Transportation Research Record 1438, TRB, National Research Council, Washington, D.C., 1994, pp 25-33.

8. Everett, M.D. The Determinants of Mass Bicycle Commuting Revisited. Journal of the Transportation Research Forum, Vol. 30, No. 2, 1990, pp. 360-366.

9. Forbes, G. The Hamilton-Wentworth Community Cycling Survey. ITE Journal, Vol. 68, No. 6, 1998, p. 16.

10. Hope, D. Nonrecreational Cycling in Ottawa, Canada. In Transportation Research Record 1441, TRB, National Research Council, Washington, D.C., 1994, pp 147-150.

11. Beck, M. and L. Immers. Bicycle Ownership and Use in Amsterdam. In Transportation Research Record 1441, TRB, National Research Council, Washington, D.C., 1994, pp 141146.

12. Aultman-Hall, L., Hall, F., and B. Baetz. Analysis Of Bicycle Commuter Routes Using Geographic Information Systems: Implications For Bicycle Planning. In Transportation Research Record 1578, TRB, National Research Council, Washington, D.C., 1997, pp 102110. 
13. Tanaboriboon, Y., and G. Ying. Characteristics of Bicycle Users in Shanghai, China. In Transportation Research Record 1396, TRB, National Research Council, Washington, D.C., 1993, pp 22-29.

14. Hanson, S. and P. Hanson. Evaluating the Impact of Weather on Bicycle Use. In Transportation Research Record 629, TRB, National Research Council, Washington, D.C., 1977, pp 43-48.

15. Ashley, C. and C. Banister. Cycling to Work from Wards in a Metropolitan Area. 1. Factors Influencing Cycling to Work. Traffic Engineering and Control, Vol. 30, No. 6, 1989, pp 297302.

16. Björsson, P. How to Encourage Cycling in Arctic Climate. Presented at Velo-City 2003 Conference, Paris, France, September 2003.

17. Perala, T. Winter Cycling in Finland, Facts and the Future. Presented at Velo-City 2003 Conference, Paris, France, September 2003.

18. Bach, B., and N. Pressman. Urban Design As An Helping Hand To Promote Bike-use; Urban Pattern Based Design Steps. Presented at Vélo Mondial 2000 Conference, Amsterdam, The Netherlands, June 2000.

19. Niemeier, D., Rutherford, G., and J. Ishimaru. An Analysis of Bicyclist Survey Responses from the Puget Sound Area and Spokane. Report 95.4, Washington State Transportation Commission, Olympia, WA, 1995.

20. Nelson, A. and D. Allen. If You Build Them, Commuters Will Use Them: Association Between Bicycle Facilities and Bicycle Commuting. In Transportation Research Record 1578, TRB, National Research Council, Washington, D.C., 1997, pp 79-83.

21. Baltes, M. Factors Influencing Nondiscretionary Work Trips by Bicycle Determined from 1990 U.S. Census Metropolitan Statistical Area Data. In Transportation Research Record 1538, TRB, National Research Council, Washington, D.C., 1996, pp 96-101.

22. Rajamani, J., Bhat, C.R., Handy, S., Knaap, G., and Y. Song. Assessing the Impact of Urban Form Measures in Nonwork Trip Mode Choice After Controlling for Demographic and Level-of-Service Effects. Transportation Research Record 1831, TRB, National Research Council, Washington, D.C., 2003, pp 158-165.

23. Schwartz, W.L., Porter, C.D., Payne, G.C., Suhrbier, J.H., Moe, P.C., and W.L. Wilkinson III. Guidebook On Methods To Estimate Non-Motorized Travel: Overview Of Methods. Publication No. FHWA-RD-98-165, Federal Highway Administration, 1999, http://www.fhwa.dot.gov/tfhrc/safety/pubs/vol1/title.htm. Accessed 2003 July 29. 
24. Stinson, M.A., and C.R. Bhat. An Analysis of Commuter Bicyclist Route Choice Using a Stated Preference Survey In Transportation Research Record 1828, TRB, National Research Council, Washington, D.C., 2003, pp 107-115.

25. Stinson, M.A. and C.R. Bhat. A Survey of Commuter Bicyclists’ Route Preferences, 2002. http://members.toast.net/quest/surveys/bikecomm2002.htm. Accessed November 15, 2003.

26. Stinson, M.A. and C.R. Bhat. A Survey of Commuter Bicyclists’ Route Preferences, 2002. http://www.ce.utexas.edu/prof/bhat/bicyclists_survey.htm. Accessed November 15, 2003.

27. McKelvey, R.D., and W. Zavonia. A Statistical Model for the Analysis of Ordinal-Level Dependent Variables. Journal of Mathematical Sociology, Vol. 4, 1975, pp.103-120.

28. Agyemang-Duah, K. and F.L. Hall. Spatial Transferability of an Ordered Response Model of Trip Generation. Transportation Research Part A, Vol. 31, No. 5, 1997, pp. 389-402.

29. Bhat, C.R. and H. Zhao. The Spatial Analysis of Activity Stop Generation. Transportation Research Part B, Vol. 36, No. 6, 2002, pp. 557-575.

30. Bhat, C. R., and S. Srinivasan. A Multidimensional Mixed Ordered-Response Model for Analyzing Weekend Activity Participation Accommodating Demographic, Internet Use, Residential Location, and Day of Week/Seasonal Effects. Technical paper, Department of Civil Engineering, The University of Texas at Austin, 2003. 


\section{LIST OF FIGURE}

FIGURE 1 Sample question about bicycle commute frequency.

\section{LIST OF TABLES}

TABLE 1 Regions Considered in the Bicycle Commute Frequency Analysis

TABLE 2 Deterrents to Commuting by Bicycle (All Commuting Respondents Used in Analysis)

TABLE 3 Reasons for Bicycling to Work (As Cited by Bicycle Commuters in the Survey)

TABLE 4 Ordered Response Model of Frequency of Commuting by Bicycle 
Question 2-3. From March through May, how often do you commute by bicycle to work? Never

About once or twice a month

About once a week

About 2-3 days per week

About 4-5 (or more) days per week

Note: Three other questions inquired about summer (June-August), fall (September-November), and winter (December-February)

FIGURE 1 Sample question about bicycle commute frequency. 
TABLE 1 Regions Considered in the Bicycle Commute Frequency Analysis

\begin{tabular}{|c|c|c|c|}
\hline Region & States & Climate Conditions & $\begin{array}{c}\text { Percentage of } \\
\text { Individuals in Sample }\end{array}$ \\
\hline Canada & Entire of Canada & Freezing winter and mild summer & 2 \\
\hline Midwestern U.S. & $\begin{array}{l}\text { Colorado, Iowa, Idaho, Illinois, Indiana, } \\
\text { Kansas, Michigan, Minnesota, Missouri, } \\
\text { Montana, North Dakota, Nebraska, South } \\
\text { Dakota, Utah, Wisconsin, and Wyoming }\end{array}$ & $\begin{array}{l}\text { Hot summer, frigid winter, cool } \\
\text { and rainy spring/fall }\end{array}$ & 21 \\
\hline Northeastern U.S. and Alaska & $\begin{array}{l}\text { Alaska, Connecticut, Massachusetts, } \\
\text { Maine, New Hampshire, New York, } \\
\text { Rhode Island, and Vermont }\end{array}$ & $\begin{array}{l}\text { Hot to mild summer, frigid } \\
\text { winter, cool and rainy spring/fall }\end{array}$ & 14 \\
\hline Mideastern U.S. & $\begin{array}{l}\text { Arkansas, Delaware, Kentucky, } \\
\text { Maryland, New Jersey, North Carolina, } \\
\text { Ohio, Pennsylvania, Tennessee, Virginia, } \\
\text { Washington, D.C., and West Virginia }\end{array}$ & $\begin{array}{l}\text { Hot summer, cold (but not frigid) } \\
\text { winter, cool spring/fall }\end{array}$ & 20 \\
\hline Southwest U.S. & $\begin{array}{l}\text { Arizona, New Mexico, Nevada, } \\
\text { Oklahoma, and Texas }\end{array}$ & $\begin{array}{l}\text { Hot and dry summer, cool winter, } \\
\text { warm spring/fall }\end{array}$ & 15 \\
\hline Southeastern U.S. & $\begin{array}{l}\text { Alabama, Florida, Georgia, Louisiana, } \\
\text { Mississippi, and South Carolina }\end{array}$ & $\begin{array}{l}\text { Warm and humid summer, cool } \\
\text { winter, warm spring/fall }\end{array}$ & 6 \\
\hline West Coast and Hawaii & $\begin{array}{l}\text { California, Hawaii, Oregon, and } \\
\text { Washington }\end{array}$ & $\begin{array}{l}\text { Mild year-round temperatures and } \\
\text { frequent rain }\end{array}$ & 22 \\
\hline
\end{tabular}


TABLE 2 Deterrents to Commuting by Bicycle (All Commuting Respondents Used in Analysis)

\begin{tabular}{|c|c|c|c|}
\hline \multirow{2}{*}{ Deterrent } & \multicolumn{3}{|c|}{$\begin{array}{c}\text { Percentage of Respondents Selecting } \\
\text { Deterrent }\end{array}$} \\
\hline & $\begin{array}{l}\text { Overall } \\
\text { Sample } \\
\end{array}$ & $\begin{array}{l}\text { Non-Bicycle } \\
\text { Commuters } \\
\end{array}$ & $\begin{array}{c}\text { Bicycle } \\
\text { Commuters } \\
\end{array}$ \\
\hline \multicolumn{4}{|l|}{$\underline{\text { Pre-specified Categories }}$} \\
\hline Unpleasant weather & 60 & 47 & 64 \\
\hline Other personal reasons (too busy, too tired, etc.) & 31 & 22 & 33 \\
\hline Not enough daylight to ride safely & 25 & 42 & 26 \\
\hline An injury or illness & 22 & 4 & 23 \\
\hline Stolen or broken bike & 6 & 4 & 6 \\
\hline Unsafe neighborhoods & 2 & 9 & 2 \\
\hline $\begin{array}{l}\text { Not applicable (respondent rides bicycle every day to } \\
\text { work) }\end{array}$ & 9 & 0 & 10 \\
\hline \multicolumn{4}{|l|}{ Write-in Categories } \\
\hline Pursuing errands & 12 & 4 & 12 \\
\hline Carrying cargo & 4 & 1 & 4 \\
\hline Distance to work too far & 2 & 27 & 3 \\
\hline Pursing passenger-serve activities & 2 & 4 & 2 \\
\hline Avoiding sweat or dressing nicely & 1 & 1 & 1 \\
\hline Dangerous traffic & 5 & 25 & 5 \\
\hline Dangerous weather & 2 & 0 & 2 \\
\hline No bicycle facilities en route to work & 1 & 8 & 1 \\
\hline No bicycle facilities at workplace & 2 & 7 & 1 \\
\hline Other & 1 & 4 & 1 \\
\hline
\end{tabular}


TABLE 3 Reasons for Bicycling to Work (As Cited by Bicycle Commuters in the Survey)

\begin{tabular}{|l|c|}
\hline \multicolumn{1}{|c|}{ Reason } & $\begin{array}{c}\text { Percentage of Bicycle } \\
\text { Commuters Selecting Reason }\end{array}$ \\
\hline \hline Pre-specified Categories & 82 \\
Fitness/health concerns & 80 \\
Pleasure/enjoyment & 58 \\
Environmental concerns related to automobile use & 25 \\
Convenience/speed & 17 \\
Avoid driving in congested conditions & 7 \\
Avoid relying on public transit & 6 \\
Limited auto parking & 1.4 \\
\hline Write-in Categories & 1.1 \\
Ideological reasons & 0.4 \\
Private automobile is unavailable & \\
\hline \hline
\end{tabular}




\section{TABLE 4 Ordered Response Model of Frequency of Commuting by Bicycle}

\begin{tabular}{|c|c|c|}
\hline Variable & Parameter & t-statistic \\
\hline \multicolumn{3}{|l|}{ Demographics } \\
\hline Female & -0.27 & -8.45 \\
\hline Number of cars in household & -0.18 & -12.64 \\
\hline \multicolumn{3}{|l|}{ Bicycle use and experience } \\
\hline Years of experience in commuting by bicycle & 0.03 & 15.63 \\
\hline Number of trip purposes by bicycle & 0.17 & 16.39 \\
\hline \multicolumn{3}{|l|}{ Work-related characteristics } \\
\hline Distance to work & -0.04 & -17.11 \\
\hline Work location in an urban area (base: rural/suburban location) & 0.12 & 4.20 \\
\hline Presence of bicycle rack or locker at workplace & 0.16 & 8.15 \\
\hline \multicolumn{3}{|l|}{ Home location (base is rural residence) } \\
\hline Urban residence & 0.23 & 4.57 \\
\hline Suburban residence & 0.11 & 2.44 \\
\hline \multicolumn{3}{|c|}{ Region of residence and season effects (base is west coast and winter season } \\
\hline \multicolumn{3}{|c|}{ Canada } \\
\hline summer & 1.11 & 5.24 \\
\hline spring/fall & 0.54 & 4.38 \\
\hline winter & -1.20 & -7.92 \\
\hline \multicolumn{3}{|l|}{ Midwestern U.S. } \\
\hline summer & 0.37 & 6.17 \\
\hline spring/fall & 0.00 & -- \\
\hline winter & -0.93 & -16.41 \\
\hline \multicolumn{3}{|l|}{ Northeastern U.S. } \\
\hline summer & 0.53 & 7.00 \\
\hline spring/fall & 0.17 & 3.22 \\
\hline winter & -0.83 & -11.78 \\
\hline \multicolumn{3}{|l|}{ Mideastern U.S. } \\
\hline summer & 0.53 & 8.63 \\
\hline spring/fall & 0.26 & 5.84 \\
\hline winter & -0.50 & -8.75 \\
\hline \multicolumn{3}{|l|}{ Southwestern U.S. } \\
\hline summer & 0.14 & 1.84 \\
\hline spring/fall & 0.00 & -- \\
\hline winter & -0.51 & -6.96 \\
\hline \multicolumn{3}{|l|}{ Southeastern U.S. } \\
\hline summer & 0.00 & -- \\
\hline spring/fall & 0.00 & -- \\
\hline winter & -0.21 & -1.87 \\
\hline \multicolumn{3}{|l|}{ West Coast } \\
\hline$\overline{\text { summer }}$ & 0.78 & 12.88 \\
\hline $\begin{array}{l}\text { spring/fall } \\
\text { winter (base) }\end{array}$ & 0.44 & 10.28 \\
\hline mu(1) & \multicolumn{2}{|c|}{0.74} \\
\hline $\mathrm{mu}(2)$ & \multicolumn{2}{|c|}{1.14} \\
\hline $\mathrm{mu}(3)$ & \multicolumn{2}{|c|}{1.99} \\
\hline $\mathbf{n}$ & \multicolumn{2}{|c|}{8376} \\
\hline Log-likelihood at convergence & \multicolumn{2}{|c|}{-10241.0} \\
\hline Log-likelihood at equal shares & \multicolumn{2}{|c|}{-11634.0} \\
\hline
\end{tabular}

